\title{
A COMPARATIVE STUDY OF MATERIAL HARDENING MODELS FOR FORMING OPERATIONS AND PREDICTION OF KINEMATIC HARDENING BY MEANS OF AN ANALYTICAL INDICATOR
}

\author{
Usama Ahmed*, Rémi Lafarge*, and Alexander Brosius* \\ ${ }^{*}$ Chair of Forming and Machining Processes (FF) \\ Technische Universität Dresden (TUD) \\ 01069 Dresden, Germany \\ e-mail: usama.ahmed@tu-dresden.de, web page: http://www.tu-dresden.de/mw/if/ff
}

Keywords: Hardening models, sheet metal forming, kinematic indicator

\begin{abstract}
Forming operations are concerned with increasing process reliability, improving tool performance, and reducing costs. The increase in quality requirements and the goal of reducing production time require increasingly accurate simulations. A large number of complex material hardening models have been developed in the past with the sole aim of accurately predicting the material behavior during forming processes [1]. It is known that in certain forming processes such as deep drawing that involve nonlinear strain paths, isotropic modeling of strain hardening is often incomplete especially in predicting the springback phenomenon as compared to more advanced models that integrate the kinematic effect [2]. Therefore, a combination of isotropic and kinematic hardening models must be employed to accurately predict this mechanism accurately. Since these models require large number of tests to include strain path changes, therefore to limit cost, these mixed hardening models should only be employed for materials exhibiting a considerable Bauschinger-effect and in situations involving highly nonlinear strain paths.
\end{abstract}

This publication is focused on comparing three different material hardening models i.e. purely isotropic, mixed hardening and purely kinematic hardening model for the simulation of forming operations. The influence of nonlinear strain paths is investigated using deep drawing and strip tensile bending experiments and their comparison with numerical simulations. This comparison enables us to determine which of the three material models is more accurate for forming operations. Subsequently, the complex nonlinear strain paths are analyzed using an analytical indicator developed at the Chair of Forming and Machining Process, TU Dresden [3], to predict the influence of kinematic hardening by comparing the experimental results with a combined material hardening model as well as a purely isotropic and kinematic material model. The analytical indicator illustrates the regions in deformed samples that are most affected by kinematic hardening and shows the difference in target values as a result of mixed and purely isotropic hardening law.

\section{References:}

[1] S. Bruschi et al., "Testing and modelling of material behaviour and formability in sheet metal forming," CIRP Ann. - Manuf. Technol., vol. 63, no. 2, pp. 727-749, 2014, doi: 10.1016/j.cirp.2014.05.005.

[2] J. Liao, X. Xue, M. G. Lee, F. Barlat, G. Vincze, and A. B. Pereira, "Constitutive modeling for path-dependent behavior and its influence on twist springback," Int. J. Plast., vol. 93, pp. $64-88,2017$, doi: 10.1016/j.jplas.2017.02.009.

[3] R. Lafarge, N. Küsters, and A. Brosius, "A novel indicator for kinematic hardening effect quantification in deep drawing simulation," COMPLASS Conf., pp. 1-12, 2019. 